\title{
Non-contiguous finished genome sequence and description of Brevibacterium senegalense sp. nov.
}

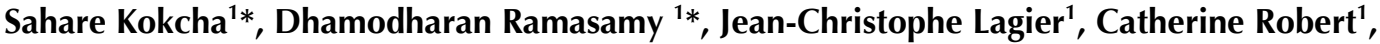 \\ Didier Raoult ${ }^{1}$ and Pierre-Edouard Fournier ${ }^{1}$ व \\ ${ }^{1}$ Aix-Marseille Université, Faculté de médecine, \\ Correspondence: Pierre-Edouard Fournier (pierre-edouard.fournier@univmed.fr)
}

Keywords: Brevibacterium senegalense, genome

Brevibacterium senegalense strain $\mathrm{JC} 43^{\top} \mathrm{sp}$. nov. is the type strain of Brevibacterium senegalense sp. nov., a new species within the Brevibacterium genus. This strain, whose genome is described here, was isolated from the fecal flora of a healthy Senegalese patient. $B$. senegalense is an aerobic rod-shaped Gram-positive bacterium. Here we describe the features of this organism, together with the complete genome sequence and annotation. The 3,425,960 bp long genome (1 chromosome but no plasmid) contains 3,064 protein-coding and 49 RNA genes.

\section{Introduction}

Brevibacterium senegalense strain JC43 ${ }^{\mathrm{T}}$ (= CSUR $\mathrm{P} 155=$ DSM 25783) is the type strain of $B$. senegalense. sp. nov. This bacterium is a nonmotile, rod-shaped, Gram-positive, catalasepositive bacterium that was isolated from the stool of a healthy Senegalese patient as part of a study aiming at cultivating individually all bacterial species within human feces.

Bacterial taxonomy has undergone many changes over recent years. The DNA-DNA hybridization and $\mathrm{G}+\mathrm{C}$ content criteria, once considered as gold standards [1], were gradually replaced by gene sequencing. In particular, $16 \mathrm{~S}$ rRNA sequencing has deeply changed the way bacteria and archaea are classified [2]. More recently, the development of high throughput genome sequencing methods and mass spectrometric analyses of bacteria have provided a wealth of genetic and proteomic information [3]. We recently used a polyphasic approach [4] that includes genomic data, MALDITOF spectrum and major phenotypic characteristics to describe new bacterial species [5-11].

The genus Brevibacterium (Breed 1953) [12] was created in 1953 to gather short non-sporeforming and non-branching rods. To date, this genus is comprised of Gram-positive, irregular, rodshaped, non-acid-fast bacteria, and contains 31 recognized species with validly published names [13]. Brevibacterium is the type genus of the family Brevibacteriaceae (Breed 1953) [14]. Members of the genus Brevibacterium are isolated from human samples, dairy products, poultry and environmental specimens. In humans, they are found on skin surfaces [15], but have also been demonstrated to cause rare cases of bacteremia, endocarditis, pericarditis, brain abscess and peritonitis. These infections have been observed mainly in immunocompromised patients [10-19], with the exception of two cases of bacteremia in immunocompetent patients with central venous catheters $[9,19]$. To date, only four Brevibacterium species have been detected in human infection, including $B$. epidermidis (Collins et al. 1983) [15,16,17], B. casei (Collins et al. 1983) [18,20], B. iodinum (Collins et al. 1981) and B. otitidis (Pascual et al. 1996).

Here we present a summary classification and a set of features for $B$. senegalense sp. nov. strain $\mathrm{JC} 3^{\mathrm{T}}$ together with the description of the complete genomic sequencing and annotation. These characteristics support the circumscription of the $B$. senegalense species.

\section{Organism information}

A stool sample was collected from a healthy 16year-old male Senegalese volunteer patient living in Dielmo (rural village in the Guinean-Sudanian zone in Senegal), who was included in a research protocol. Written assent was obtained from this individual. No written consent was needed from his guardians for this study because he was older than 15 years old (in accordance with the previous project approved by the Ministry of Health of Senegal

The Genomic Standards Consortium 
and the assembled village population, and as published elsewhere [20]. Both this study and the assent procedure were approved by the National Ethics Committee of Senegal (CNERS) and the Ethics Committee of the Institut Fédératif de Recherche IFR48, Faculty of Medicine, Marseille, France (agreement numbers 09-022 and 11-017)). Several other new bacterial species were isolated from this specimen using various culture conditions, including the recently described Alistipes timonensis, A. senegalensis, Anaerococcus senegalensis, Bacillus timonensis, Clostridium senegalense, Paenibacillus senegalensis, and Peptoniphilus timonensis [5-11]. The fecal specimen was preserved at $-80^{\circ} \mathrm{C}$ after collection and sent to Marseille. Strain JC43 ${ }^{\mathrm{T}}$ (Table 1) was isolated in December 2010 after inoculation on Brucella agar (BD diagnostic, Heilderberg, Germany), in aerobic atmosphere at $37^{\circ} \mathrm{C}$.
The strain exhibited 97.1 and $96.7 \%$ nucleotide sequence similarities with $B$. salitolerans (Guan et al. 2010) and B. album (Tang et al. 2008), respectively, the phylogenetically closest validated Brevibacterium species (Figure 1). These values were lower than the $98.7 \%$ 16S rRNA gene sequence threshold recommended by Stackebrandt and Ebers to delineate a new species without carrying out DNA-DNA hybridization [2]. In comparison to $16 \mathrm{~S}$ sequences in the GenBank database [30], strain JC43 ${ }^{\mathrm{T}}$ also exhibited nucleotide sequence similarities greater than $98.7 \%$ with uncultured bacterial clones detected in watermiscible metalworking fluids [31] and on clean room surfaces [32]. These bacteria most likely belong to the same species as strains JC43 (Figure 1).

Table 1. Classification and general features of Brevibacterium senegalense strain $\mathrm{JC}^{\mathrm{C}} 3^{\top}$ according to the MIGS recommendations [21]

\begin{tabular}{|c|c|c|c|}
\hline MIGS ID & Property & Term & Evidence code $^{\mathrm{a}}$ \\
\hline & \multirow{8}{*}{ Current classification } & Domain Bacteria & TAS [22] \\
\hline & & Phylum Actinobacteria & TAS [23] \\
\hline & & Class Actinobacteria & TAS [24] \\
\hline & & Order Actinomycetales & TAS [24-27] \\
\hline & & Family Brevibacteriaceae & TAS $[24,25,27,28]$ \\
\hline & & Genus Brevibacterium & TAS $[14,25]$ \\
\hline & & Species Brevibacterium senegalensis & IDA \\
\hline & & Type strain JC43 ${ }^{\top}$ & IDA \\
\hline & Gram stain & positive & IDA \\
\hline & Cell shape & rod & IDA \\
\hline & Motility & nonmotile & IDA \\
\hline & Sporulation & nonsporulating & IDA \\
\hline & Temperature range & Mesophile & IDA \\
\hline & Optimum temperature & $30-37^{\circ} \mathrm{C}$ & IDA \\
\hline MIGS-6.3 & Salinity & unknown & IDA \\
\hline \multirow[t]{3}{*}{ MIGS-22 } & Oxygen requirement & aerobic & IDA \\
\hline & Carbon source & glucose & \\
\hline & Energy source & chemoorganotrophic & \\
\hline MIGS-6 & Habitat & human gut & IDA \\
\hline \multirow[t]{3}{*}{ MIGS-15 } & Biotic relationship & free living & IDA \\
\hline & Pathogenicity & Unknown & \\
\hline & Biosafety level & 2 & \\
\hline MIGS-14 & Isolation & human feces & \\
\hline MIGS-4 & Geographic location & Senegal & IDA \\
\hline MIGS-5 & Sample collection time & September 2010 & IDA \\
\hline \multirow[t]{2}{*}{ MIGS-4. 1} & Latitude - & 13.7167 & IDA \\
\hline & Longitude & -16.4167 & \\
\hline MIGS-4.3 & Depth & surface & IDA \\
\hline MIGS-4.4 & Altitude & $51 \mathrm{~m}$ above sea level & IDA \\
\hline
\end{tabular}

aEvidence codes - IDA: Inferred from Direct Assay (first time in publication); TAS: Traceable Author Statement (a direct report exists in the literature); NAS: Non-traceable Author Statement (not directly observed for the living, isolated sample, but based on a generally accepted property of the species, or anecdotal evidence). These evidence codes are from the Gene Ontology project [29]. 


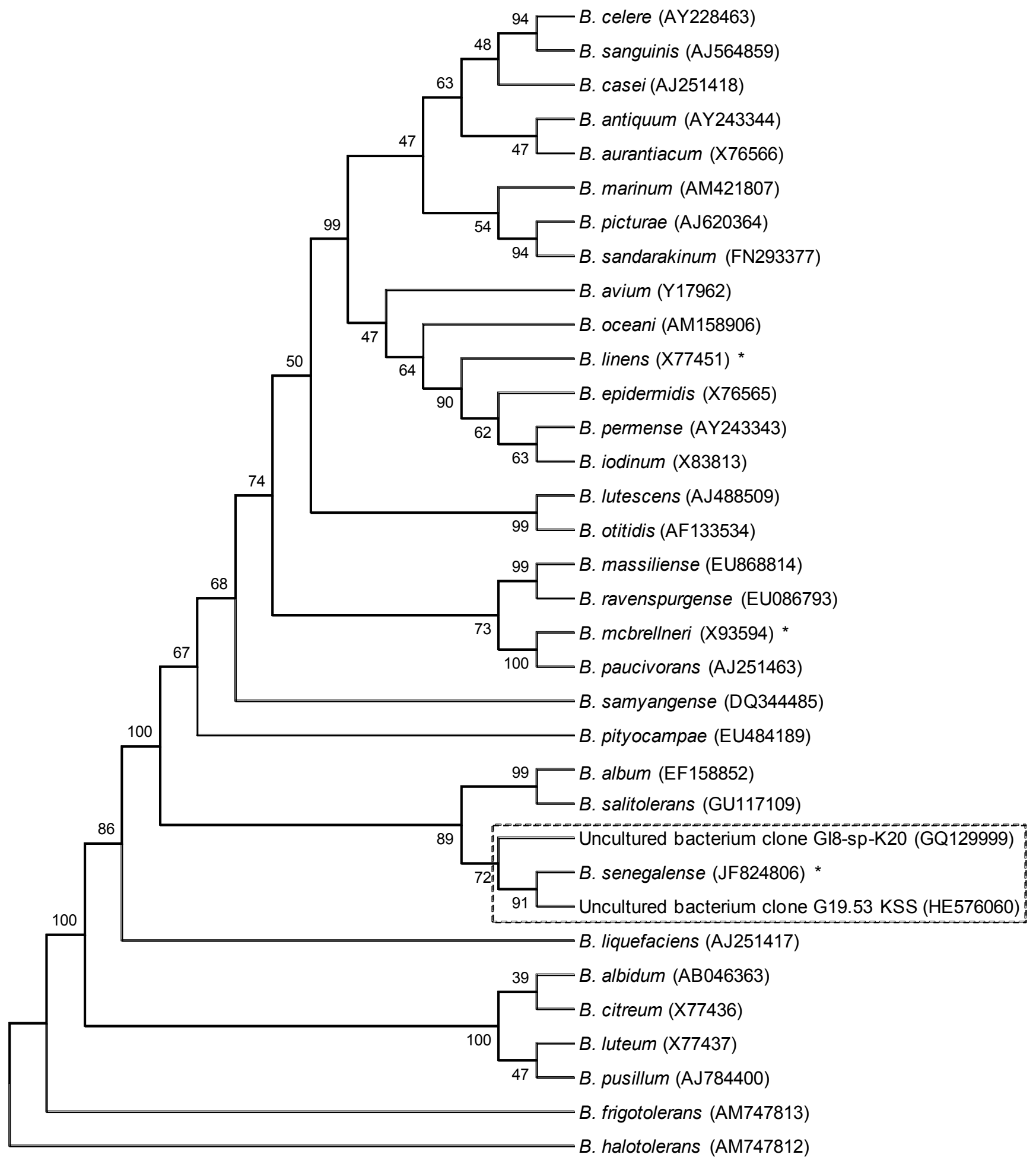

Figure 1. Phylogenetic tree highlighting the position of Brevibacterium senegalense strain JC43 ${ }^{\top}$ relative to other type strains within the genus Brevibacterium. GenBank accession numbers are indicated in parentheses. Sequences were aligned using CLUSTALW, and phylogenetic inferences obtained using the maximum-likelihood method within the MEGA software. Numbers at the nodes are percentages of bootstrap values obtained by repeating 500 times the analysis to generate a majority consensus tree. The dashed-line square shows sequences that exhibit degrees of similarity $>99 \%$ with $B$. senegalense (same species). Asterisks indicate the species for which genome sequences are currently available. 
Different growth temperatures $\left(25,30,37,45^{\circ} \mathrm{C}\right)$ were tested; no growth occurred at $45^{\circ} \mathrm{C}$, weak growth occurred at $25^{\circ} \mathrm{C}$, and optimal growth was observed between 30 to $37^{\circ} \mathrm{C}$.

Colonies were translucent and smooth, with a diameter of $1 \mathrm{~mm}$ on blood-enriched Columbia agar and Brain Heart Infusion (BHI) agar. Growth of the strain was tested under anaerobic and microaerophilic conditions using GENbag anaer and GENbag microaer systems, respectively (BioMérieux), and in the presence of air, of $5 \%$ $\mathrm{CO}_{2}$ and in aerobic conditions. Optimal growth was obtained aerobically and with $5 \% \mathrm{CO}_{2}$. Weak growth was observed under microaerophilic conditions. No growth was observed in an anaerobic atmosphere.

Gram staining showed Gram-positive rods. A motility test was negative. Cells grown on agar are Gram-positive (Figure 2) and are mostly grouped in small clumps (Figure 3). Their length and width range from 0.83 to $3.86 \mu \mathrm{m}$ (mean, $2.55 \mu \mathrm{m}$ ) and 0.57 to $0.78 \mu \mathrm{m}$ (mean, $0.68 \mu \mathrm{m}$ ), respectively.

Strain JC43T exhibited catalase activity but not oxidase activity. Using the API CORYNE system(BioMérieux), positive reactions were observed for nitrate reduction, pyrrolidonyl arylamidase, alkaline phosphatase, $\alpha$-glucosidase. A weak reaction was observed for gelatin hydrolysis. Negative reactions were observed for urease, pyrazinamidase, $\beta$-glucuronidase, $\beta$-galactosidase, $\alpha$-glucosidase, $\quad \mathrm{N}$-acetyl- $\beta$-glucosaminidase, $\beta$ glucosidase (aesculin hydrolysis), and acid production from D-ribose, D-glucose, D-xylose, Dmannitol, maltose, D-lactose, sucrose and glycogen. Using API ZYM (BioMérieux), positive reactions were observed for esterase (C4), esterase lipase (C8), leucine arylamidase and acid and alkaline phosphatase. Negative reactions were observed for valine arylamidase, cystine arylamidase, trypsin, $\alpha$-chymotrypsin, naphtol-ASBI-phosphohydrolase, lipase, $\alpha$-galactosidase, $\beta$ galactosidase, $\beta$-glucuronidase, $\alpha$-glucosidase, $\beta$ glucosidase, $\quad \mathrm{N}$-acetyl- $\beta$-glucosaminidase, $\alpha$ mannosidase and $\alpha$-fucosidase. B. senegalense is susceptible to penicillin $\mathrm{G}$, amoxicillin, imipenem, ciprofloxacin, rifampin, gentamicin, doxycycline and vancomycin but resistant to trimethoprim/sulfamethoxazole and metronidazole. By comparison to B. salitolerans [33] and B. album [34], B. senegalense strain JC43 ${ }^{\mathrm{T}}$ differed in growth temperature, gelatin hydrolysis, pyrazinamidase, acid production from D-ribose, and nitrate reduction. In addition, $B$. senegalense also differed from the former species in $\beta$-glucosidase (aesculin hydrolysis) activity [33], and from the latter species in motility, valine arylamidase, cystine arylamidase, trypsin, $\alpha$-chymotrypsin and naphtol-AS-BI-phosphohydrolase activities [34].

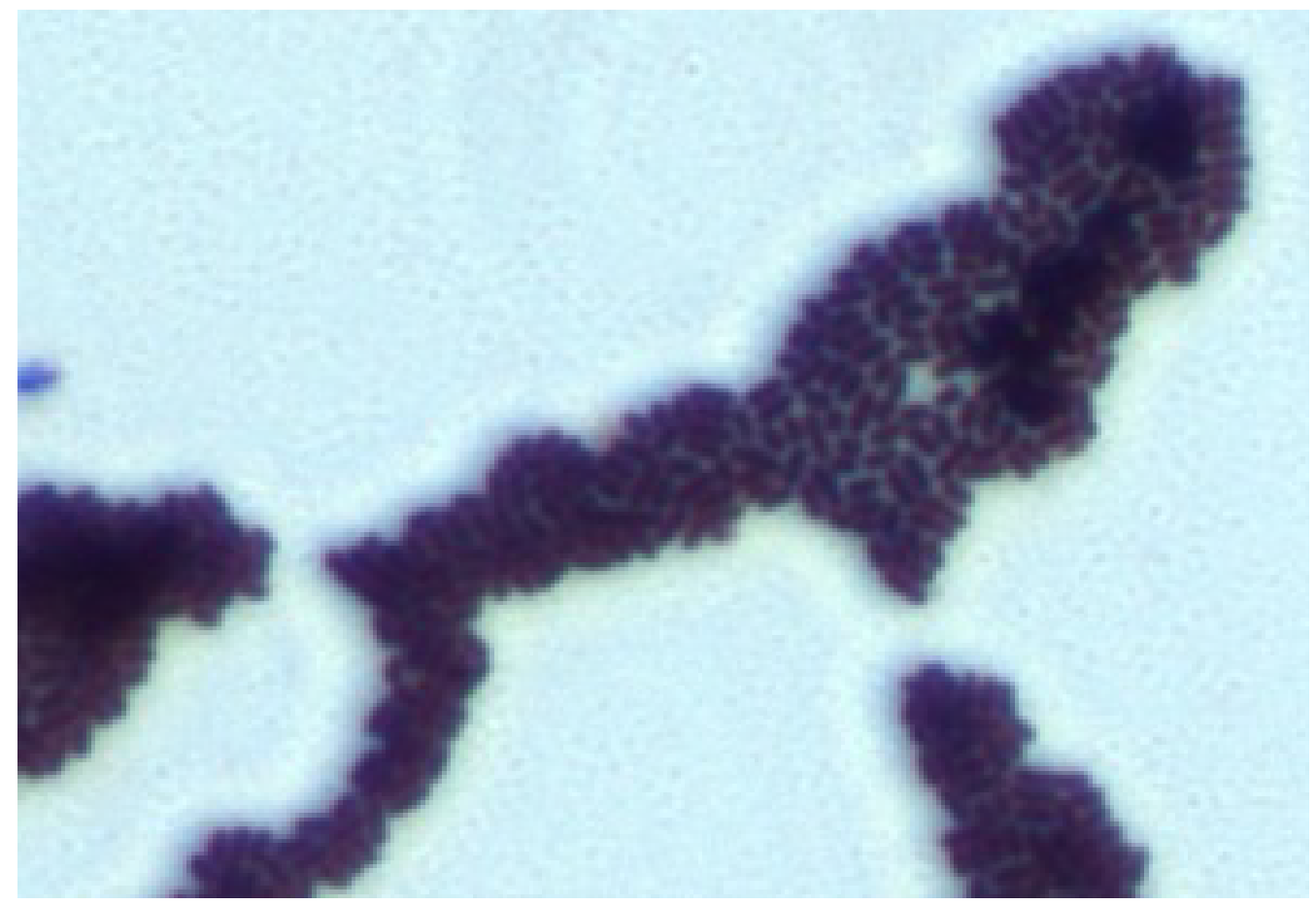

Figure 2. Gram staining of B. senegalense strain $\mathrm{JC} 43^{\mathrm{T}}$ 


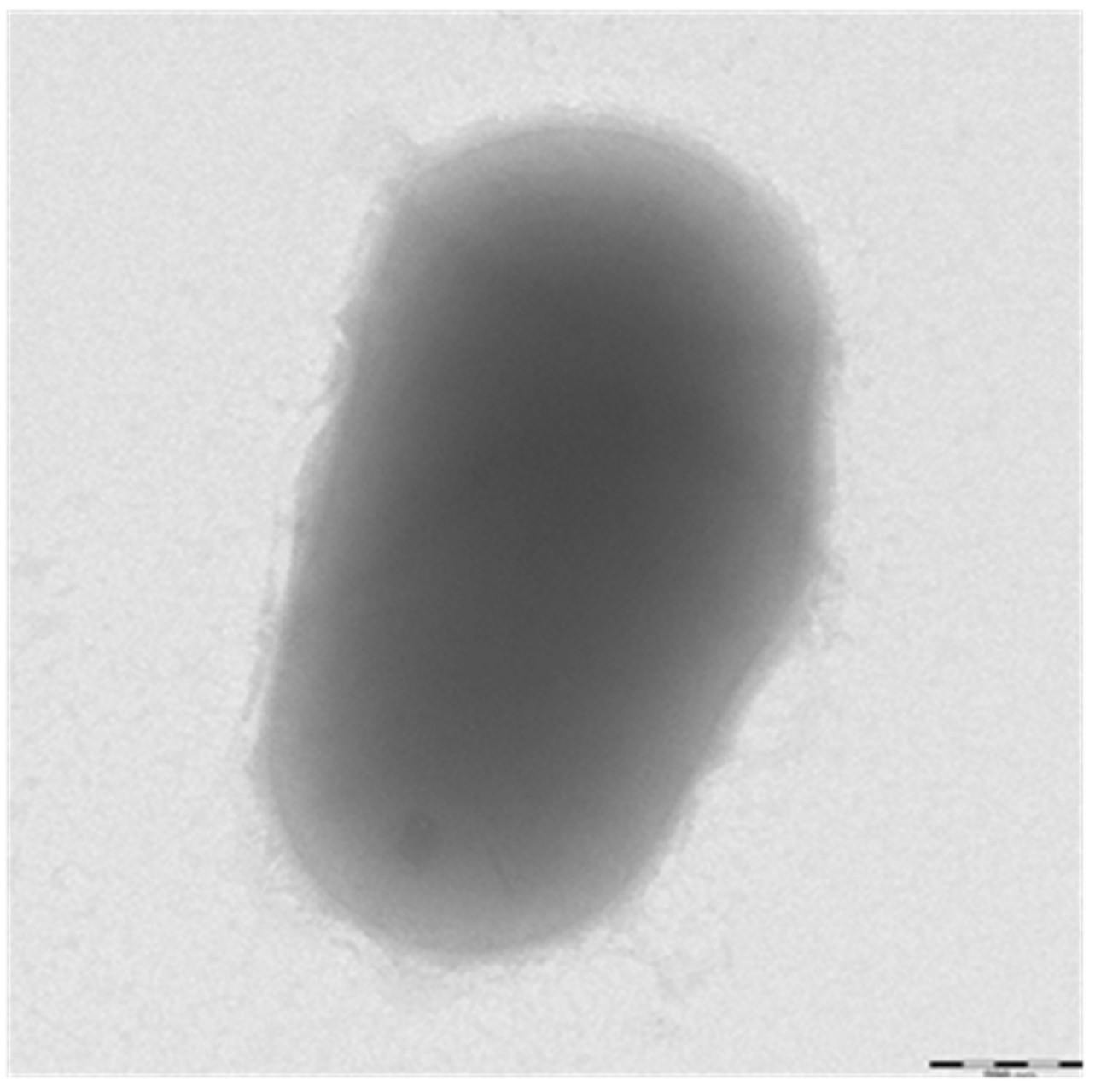

Figure 3. Transmission electron microscopy of $B$. senegalense strain $\mathrm{JC}{ }^{\top}{ }^{\top}$, using a Morgani 268D (Philips) at an operating voltage of $60 \mathrm{kV}$. The scale bar represents $200 \mathrm{~nm}$.

Matrix-assisted laser-desorption/ionization timeof-flight (MALDI-TOF) MS protein analysis was carried out as previously described [5,35] using a Microflex spectrometer (Bruker Daltonics, Germany). Twelve distinct deposits were done for strain JC43 ${ }^{\mathrm{T}}$ from four isolated colonies. The 12 $\mathrm{JC43}^{\mathrm{T}}$ spectra were imported into the MALDI BioTyper software (version 2.0, Bruker) and analyzed by standard pattern matching (with default parameter settings) against the main spectra of 3,769 bacteria, which were used as reference data, in the BioTyper database. The database contained 41 spectra from 18 validly published Brevibacterium species, including $B$. avium, $B$. celere, B. casei, B. aurantiacum, B. epidermidis, B. iodinum, $B$. linens, $B$. luteolum, B. marinum, $B$. massiliense, B. mcbrellneri, $B$. otitidis, $B$. paucivorans, $B$. picturae, $B$. pityocampae, $B$. ravenspurgense, $B$. sanguinis and $B$. stationis. No significant score was obtained for strain JC43, thus suggesting that our isolate was not a member of a known Brevibacterium species within the Bruker database. We incremented our database with the spectrum from strain JC43 (Figure 4).

\section{Genome sequencing and annotation Genome project history}

The organism was selected for sequencing on the basis of its phylogenetic position and 16S rRNA similarity to other members of the Brevibacterium genus, and is part of a study aiming at isolating all bacterial species within human feces. It was the third genome of a Brevibacterium species. The genome EMBL accession number is CAHK00000000 and consists of 80 contigs. Table 2 shows the project information and its association with MIGS version 2.0 compliance. 


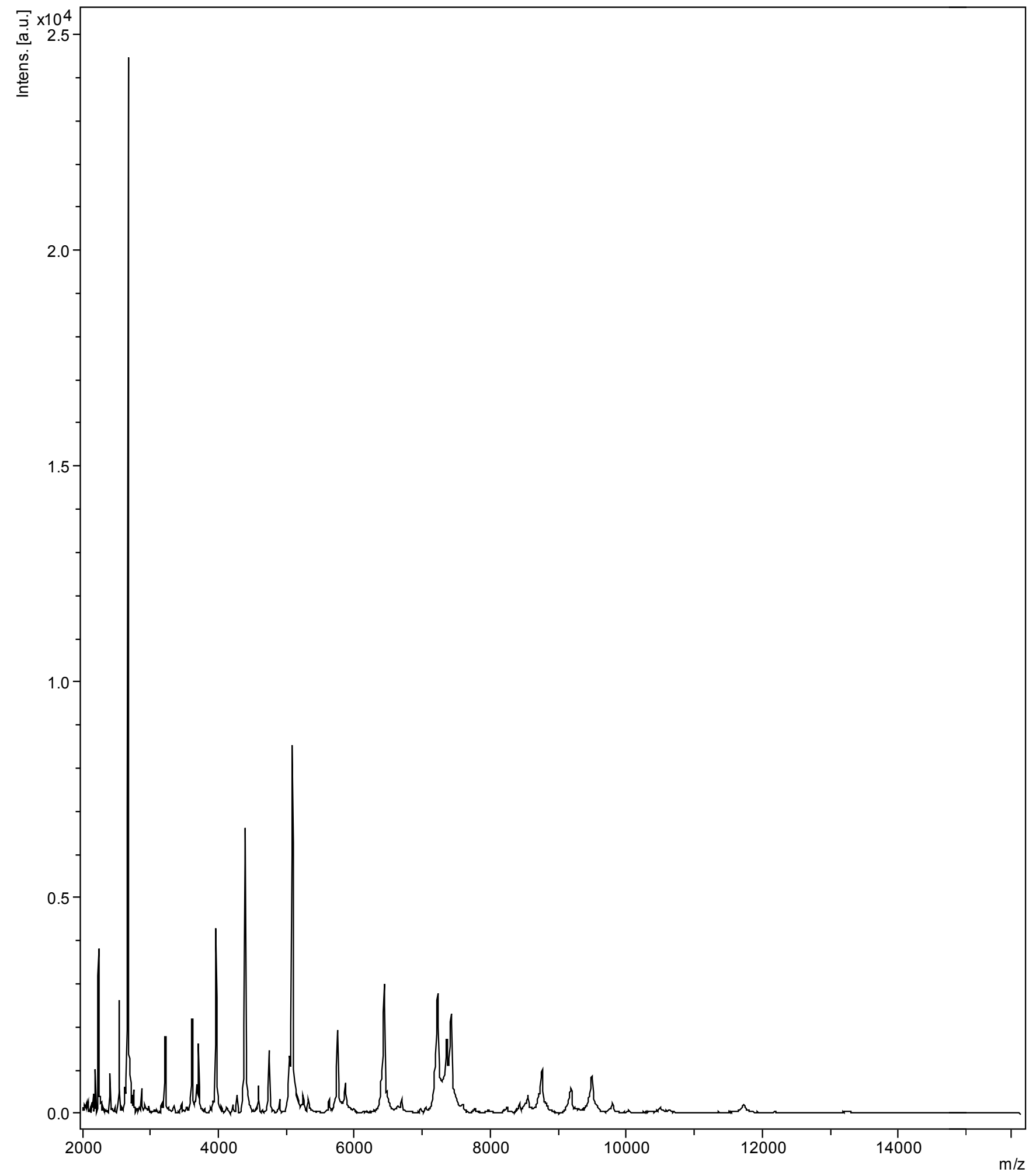

Figure 4. Reference mass spectrum from $B$. senegalense strain $\mathrm{JC} 3^{\top}$. Spectra from 4 individual colonies were compared and a reference spectrum was generated. 
Table 2. Project information

\begin{tabular}{lll}
\hline MIGS ID & Property & Term \\
\hline MIGS-31 & Finishing quality & High quality draft \\
MIGS-28 & Libraries used & One shotgun, one paired-end 3-kb \\
MIGS-29 & Sequencing platforms & 454 GS FLX Titanium \\
MIGS-31.2 & Fold coverage & $20 \times$ \\
MIGS-30 & Assemblers & Newbler version 2.5.3 \\
MIGS-32 & Gene calling method & Prodigal \\
& EMBL ID & CAHK00000000 \\
& EMBL date of Release & February 2, 2012 \\
& Project relevance & Study of the human gut microbiot \\
\hline
\end{tabular}

\section{Growth conditions and DNA isolation}

B. senegalense $\mathrm{sp}$. nov. strain JC43 ${ }^{\mathrm{T}}$ (CSUR $=\mathrm{P} 155$, $\mathrm{DSM}=25783$ ) was grown aerobically on $5 \%$ sheep blood-enriched Columbia agar at $37^{\circ} \mathrm{C}$. Seven petri dishes were spread and resuspended in $3 \times 100 \mu l$ of G2 buffer (EZ1 DNA Tissue kit, Qiagen). A first mechanical lysis was performed by glass powder on the Fastprep-24 device (Sample Preparation system; MP Biomedicals, USA) using 2x20 seconds cycles. DNA was then treated with $2.5 \mu \mathrm{g} / \mu \mathrm{L}$ lysozyme $(30$ minutes at $37^{\circ} \mathrm{C}$ ) and extracted through the BioRobot EZ 1 Advanced XL (Qiagen). The DNA was then concentrated and purified on a Qiamp kit (Qiagen). The yield and the concentration was measured by the Quant-it Picogreen kit (Invitrogen) on the Genios_Tecan fluorometer at $68,1 \mathrm{ng} / \mu \mathrm{l}$.

\section{Genome sequencing and assembly}

A shotgun library and a $3 \mathrm{~kb}$ paired end library were pyrosequenced on the 454 Roche Titanium sequencing platform. This project was loaded on one $1 / 4$ region region of PTP Picotiterplate (Roche, Meylan, France) for the shotgun library and $4 \times 1 / 4$ region for the 3-kb paired-end library. The shotgun library was constructed with 500 ng of DNA with the GS Rapid library Prep kit as described by the manufacturer (Roche). For the paired-end library, $5 \mu \mathrm{g}$ of DNA was mechanically fragmented on a Hydroshear device (Digilab, Holliston, MA, USA) with an enrichment size at 3-4kb. DNA fragmentation was visualized using an Agilent 2100 BioAnalyzer on a DNA labchip 7500 with an optimal size of $3.692 \mathrm{~kb}$. The library was constructed according to the 454 Titanium paired-end protocol (Roche). Circularization and nebulization were performed and generated a pattern with an optimum of $510 \mathrm{bp}$. After PCR amplification through 15 cycles followed by double size selection, the single stranded paired-end library was then quantified using a Quant-it Ribogreen kit (Invitrogen) on a Genios Tecan fluorometer at $245 \mathrm{pg} / \mu \mathrm{L}$. The library concentration equivalence was calculated at $8.80 \mathrm{E}+08$ molecules $/ \mu \mathrm{L}$. The libraries were stocked at $-20^{\circ} \mathrm{C}$ until further use.

The shotgun library was clonally amplified with 3 cpb in 3 emPCR reactions and the 3 -kb paired-end library was amplified with $1 \mathrm{cpb}$ in 10 emPCR reactions and $0.25 \mathrm{cpb}$ in $4 \mathrm{emPCR}$ with the GS Titanium SV emPCR Kit (Lib-L) v2 (Roche). The yield of the shotgun emPCR reactions was higher than expected at $24 \%$, but the yields of the two types of paired-end emPCR were $16.7 \%$ and $11.01 \%$, respectively, in the range of 5 to $20 \%$ from the Roche procedure.

The libraries were loaded on the GS Titanium PicoTiterPlate PTP Kit $70 \times 75$ and sequenced with the GS FLX Titanium Sequencing Kit XLR70 (Roche). The runs were performed overnight and then analyzed on the cluster through the gsRunBrowser and Newbler Assembler (Roche). A total of 752,121 passed filter wells were obtained and generated $203.1 \mathrm{Mb}$ of sequence with an average length of $265 \mathrm{bp}$. The passed filter sequences were assembled using Newbler with $90 \%$ identity and $40 \mathrm{bp}$ as overlap. The final assembly identified 80 contigs ( $>500 \mathrm{bp}$ ) arranged into 16 scaffolds and generated a genome size of $3.42 \mathrm{Mb}$.

\section{Genome annotation}

Open Reading Frames (ORFs) were predicted using Prodigal [36] with default parameters but the predicted ORFs were excluded if they were spanning a sequencing GAP region. The predicted bacterial protein sequences were searched against the GenBank database and the Clusters of Orthologous Groups (COG) database using BLASTP. The 
tRNAScanSE tool [37] was used to find tRNA genes, whereas ribosomal RNAs were found using RNAmmer [38]. Transmembrane domains and signal peptides were predicted using TMHMM [39] and SignalP [40], respectively. ORFans were identified if their BLASTp $E$-value was lower than 1e-03 for alignment length greater than 80 amino acids. If alignment lengths were smaller than 80 amino acids, we used an $E$-value of $1 \mathrm{e}-05$. To estimate the mean level of nucleotide sequence similarity at the genome level between $B$. senegalense, $B$. linens (GenBank accession number AAGP00000000) and B. mcbrellneri (ADNU00000000) we compared the ORFs only using BLASTN at a query coverage of $\geq$ $70 \%$ and a minimum nucleotide length of $100 \mathrm{bp}$.

\section{Genome properties}

The genome is 3,425,960 bp long ( 1 chromosome, but no plasmid) with a $70.00 \% \mathrm{G}+\mathrm{C}$ content (Table 3 and Figure 5). Of the 3,114 predicted genes, 3,065 were protein-coding genes and 49 were RNAs, including 3 rRNA operons (5S, $16 \mathrm{~S}$ and $23 \mathrm{~S}$ rRNA) and 40 tRNAs. A total of 2,077 genes $(66.7 \%)$ were assigned a putative function. The distribution of genes into COGs functional categories is presented in Table 4 and Figure 5. The properties and the statistics of the genome are summarized in Tables 3 and 4.

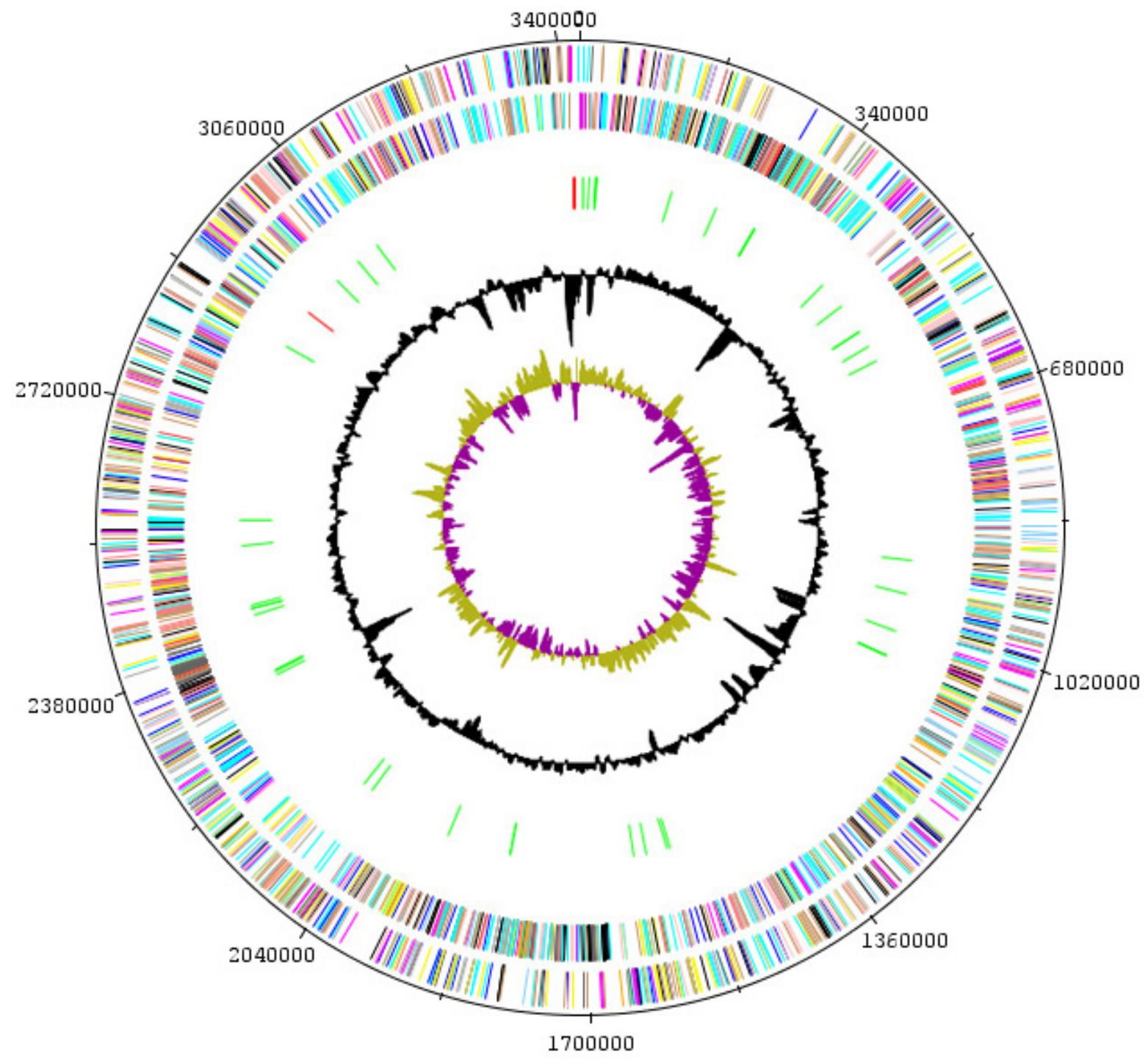

Figure 5. Graphical circular map of the Brevibacterium senegalense genome. From outside to the center: genes on the forward strand (colored by COG categories), genes on the reverse strand (colored by COG categories), RNA genes (tRNAs, green; rRNAs, red), G+C content, GC skew. 
Table 3. Nucleotide content and gene count levels of the genome

\begin{tabular}{lrr}
\hline Attribute & Value & \% of total $^{\mathbf{a}}$ \\
\hline Genome size (bp) & $3,425,960$ & 100 \\
DNA coding region (bp) & $3,115,812$ & 90.94 \\
DNA G+C content (bp) & $2,398,172$ & 70.00 \\
Total genes & 3,114 & 100 \\
RNA genes & 49 & 1.57 \\
Protein-coding genes & 3,064 & 98.39 \\
Genes with function prediction & 2,378 & 76.36 \\
Genes assigned to COGs & 2,077 & 66.69 \\
Genes with peptide signals & 181 & 5.8 \\
Genes with transmembrane helices & 317 & 10.17 \\
\hline
\end{tabular}

The total is based on either the size of the genome in base pairs or the total number of protein coding genes in the annotated genome

Table 4. Number of genes associated with the 25 general COG functional categories

\begin{tabular}{crrl}
\hline Code & Value & \% $^{\text {of }}$ total $^{\mathbf{a}}$ & Description \\
\hline J & 149 & 4.86 & Translation \\
A & 1 & 0.032 & RNA processing and modification \\
K & 163 & 5.31 & Transcription \\
L & 176 & 5.74 & Replication, recombination and repair \\
B & 0 & 0 & Chromatin structure and dynamics \\
D & 24 & 0.78 & Cell cycle control, mitosis and meiosis \\
Y & 0 & 0 & Nuclear structure \\
V & 47 & 1.53 & Defense mechanisms \\
T & 52 & 1.69 & Signal transduction mechanisms \\
M & 105 & 3.42 & Cell wall/membrane biogenesis \\
N & 0 & 0 & Cell motility \\
Z & 0 & 0 & Cytoskeleton \\
W & 0 & 0 & Extracellular structures \\
U & 26 & 0.84 & Intracellular trafficking and secretion \\
O & 76 & 2.47 & Posttranslational modification, protein turnover, chaperones \\
C & 139 & 4.53 & Energy production and conversion \\
G & 88 & 2.87 & Carbohydrate transport and metabolism \\
E & 189 & 6.16 & Amino acid transport and metabolism \\
F & 63 & 2.05 & Nucleotide transport and metabolism \\
H & 72 & 2.34 & Coenzyme transport and metabolism \\
I & 123 & 4.01 & Lipid transport and metabolism \\
P & 127 & 4.14 & Inorganic ion transport and metabolism \\
Q & 25 & 0.81 & Secondary metabolites biosynthesis, transport and catabolism \\
R & 250 & 8.15 & General function prediction only \\
S & 182 & 5.93 & Function unknown \\
- & 301 & 9.82 & Not in COGs \\
\hline & & & \\
\hline
\end{tabular}

${ }^{\text {a }}$ The total is based on the total number of protein coding genes in the annotated genome 


\section{Genomic comparison with $B$. linens and $B$. mcbrellneri}

Currently, two draft genomes from Brevibacterium species are available. By comparison with $B$. linens strain BL2 (GenBank accession number AAGP00000000) and B. mcbrellneri strain ATCC 49030 (ADNU00000000) B. senegalense strain $\mathrm{JC4}^{\mathrm{T}}$ has a smaller genome than the former (3.42 $\mathrm{Mb}$ vs $4.37 \mathrm{Mb}$ ) but larger than the latter $(2.56 \mathrm{Mb})$. $B$. senegalense also has a higher $\mathrm{G}+\mathrm{C}$ content than the other two genomes $(70.00 \%$ vs $62.8 \%$ and $58.00 \%$, respectively); it has a smaller number of predicted genes $(3,114)$ than $B$. linens $(4,054)$ but greater than $B$. mcbrellneri $(2,437)$. Finally, at the genome level, $B$. senegalense exhibited percentages of nucleotide sequence similarity of $86.28 \%$ (range $70.01-100 \%$ ) and $70.19 \%$ (range $86.09-100 \%$ ) with $B$. linens and B. mcbrellneri, respectively.

\section{Conclusion}

On the basis of phenotypic (Table 5), phylogenetic and genomic analyses, we formally propose the creation of Brevibacterium senegalense sp. nov. that contains the strain JC43T. This bacterium originated from Senegal.

Table 5. Phenotypic differences observed between B. senegalense strain JC43T, B. salitolerans strain YIM90718 and B. album strain TRM415.

\begin{tabular}{|c|c|c|c|}
\hline & B. senegalense $J C 43^{T}$ & B. album TRM415 & B. salitolerans YIM90718 \\
\hline Motility & - & + & - \\
\hline Catalase & + & + & + \\
\hline Oxydase & - & - & - \\
\hline Spore-forming & - & - & - \\
\hline $\mathrm{T}^{\circ}$ of growth & $25-37^{\circ} \mathrm{C}$ & $28-45^{\circ} \mathrm{C}$ & $15-50^{\circ} \mathrm{C}$ \\
\hline Gelatin hydrolysis & W & + & + \\
\hline Alkaline phosphatase & + & + & + \\
\hline Esterase lipase C8 & + & + & NA \\
\hline Pyrazinamidase & - & + & + \\
\hline Nitrate reduction & + & - & - \\
\hline Bglucuronidase & - & - & - \\
\hline$\beta$ galactosidase & - & - & - \\
\hline $\mathrm{N}$-acetyl- $\beta$ glucosamidase & - & - & - \\
\hline Bglucosidase (aesculin hydrolysis) & - & - & + \\
\hline eglucosidase & - & - & - \\
\hline urease & - & - & - \\
\hline \multicolumn{4}{|l|}{ Acid production for } \\
\hline D-ribose & - & + & + \\
\hline D-glucose & - & _- & - \\
\hline
\end{tabular}

\section{Description of Brevibacterium senegalense sp. nov.} Brevibacterium senegalense (se.ne.gal.e'n.se L. gen. neutr. n. senegalense, pertaining to, or originating from Senegal, the country from which the specimen that enabled isolation of $B$. senegalense was isolated.)

Colonies are translucent, smooth and have a diameter of $1 \mathrm{~mm}$ on blood-enriched Columbia agar and Brain Heart Infusion (BHI) agar. Cells are rodshaped and occur mostly in small clumps. Their length and width range from 0.83 to $3.86 \mu \mathrm{m}$ (mean, $2.55 \mu \mathrm{m}$ ) and 0.57 to $0.78 \mu \mathrm{m}$ (mean, 0.68 $\mu \mathrm{m})$, respectively. Optimal growth is achieved aerobically with or without $\mathrm{CO}_{2}$. Weak growth is observed under microaerophilic conditions. No growth is observed under anaerobic conditions. Growth occurs between $30-37^{\circ} \mathrm{C}$. Cells stain Grampositive, are non-endospore-forming, and nonmotile. Catalase, nitrate reduction, pyrrolidonyl arylamidase, alkaline phosphatase, $\alpha$-glucosidase, gelatin hydrolysis, esterase (C4), esterase lipase (C8), leucine arylamidase and acid and alkaline phosphatase activities are present. Urease, pyrazinamidase, $\beta$-glucuronidase, $\beta$-galactosidase, $\alpha$-glucosidase, $\quad \mathrm{N}$-acetyl- $\beta$-glucosaminidase, $\beta$ glucosidase (aesculin hydrolysis), acid production from D-ribose, D-glucose, D-xylose, D-mannitol, maltose, D-lactose, sucrose and glycogen, valine aylamidase, cystine aylamidase, trypsin, $\alpha$ - 
chymotrypsin, naphtol-AS-BI-phosphohydrolase, lipase, $\quad \alpha$-galactosidase, $\beta$-galactosidase, $\beta$ glucuronidase, $\alpha$-glucosidase, $\beta$-glucosidase, $N$ acetyl- $\beta$-glucosaminidase, $\alpha$-mannosidase and $\alpha$ fucosidase activities are absent. Oxidase activity is absent. Cells are susceptible to penicillin G, amoxicillin, imipenem, ciprofloxacin, rifampin, gentamicin, doxycycline and vancomycin, but resistant to

\section{References}

1. Rossello-Mora R. DNA-DNA reassociation methods applied to microbial taxonomy and their critical evaluation. In: Stackebrandt E (ed.), Molecular Identification, Systematics, and Population Structure of Prokaryotes. Springer-Verlag, Berlin, 2006, p. 23-50.

2. Stackebrandt E, Ebers J. Taxonomic parameters revisited: tarnished gold standards. Microbiol Today 2006; 33:152-155.

3. Welker M, Moore ER. Applications of whole-cell matrix-assisted laser-desorption/ionization timeof-flight mass spectrometry in systematic microbiology. Syst Appl Microbiol 2011; 34:2-11. PubMed http://dx.doi.org/10.1016/j.syapm.2010.11.013

4. Tindall BJ, Rossello-Mora R, Busse HJ, Ludwig W, Kämpfer P. Notes on the characterization of prokaryote strains for taxonomic purposes. Int I Syst Evol Microbiol 2010; 60:249-266. PubMed http://dx.doi.org/10.1099/ijs.0.016949-0

5. Lagier JC, El Karkouri K, Nguyen TT, Armougom F, Raoult D, Fournier PE. Non-contiguous finished genome sequence and description of Anaerococcus senegalensis sp. nov. Stand Genomic Sci 2012; 6:116-125. PubMed http://dx.doi.org/10.4056/sigs.2415480

6. Kokcha S, Mishra AK, Lagier JC, Million M, Leroy Q, Raoult D, Fournier PE. Non contiguousfinished genome sequence and description of $\mathrm{Ba}$ cillus timonensis sp. nov. Stand Genomic Sci $2012 ; \mathbf{6}: 346-355$. http://dx.doi.org/10.4056/sigs.2776064

7. Mishra AK, Gimenez G, Lagier JC, Robert C, Raoult D, Fournier PE. Non-contiguous finished genome sequence and description of Alistipes senegalensis sp. nov. Stand Genomic Sci 2012; 6:304-314. http://dx.doi.org/10.4056/sigs.2625821

8. Lagier JC, Armougom F, Mishra AK, Ngyuen TT, Raoult D, Fournier PE. Non-contiguous finished trimethoprim/sulfamethoxazole and metronidazole.

The $\mathrm{G}+\mathrm{C}$ content of the genome is $70.00 \%$. The 16S rRNA and genome sequences are deposited in EMBL under accession numbers JF824806 and CAHK00000000, respectively.

The type strain JC43 ${ }^{\mathrm{T}}(=$ CSUR P $155=\mathrm{DSM}$ 25783) was isolated from the fecal flora of a healthy patient in Senegal.

genome sequence and description of Alistipes timonensis sp. nov. Stand Genomic Sci 2012; 6:315-324. http://dx.doi.org/10.4056/sigs.2685917

9. Mishra AK, Lagier JC, Robert C, Raoult D, Fournier PE. Non-contiguous finished genome sequence and description of Clostridium senegalense sp. nov. Stand Genomic Sci 2012; 6:386-395.

10. Mishra AK, Lagier JC, Robert C, Raoult D, Fournier PE. Non-contiguous finished genome sequence and description of Peptoniphilus timonensis sp. nov. Stand Genomic Sci 2012; 7:111. http://dx.doi.org/10.4056/sigs.2956294

11. Mishra AK, Lagier JC, Rivet R, Raoult D, Fournier $P E$. Non-contiguous finished genome sequence and description of Paenibacillus senegalensis sp. nov. Stand Genomic Sci 2012; 7:70-81. http://dx.doi.org/10.4056/sigs.3054650

12. Breed RS. The families developed from Bacteriaceae Cohn with a description of the family Brevibacteriaceae. Riassunti delle

Communicazione VI. Congresso Internazionale di Microbiologia, Roma 1953; 5:10-15.

13. List of Prokaryotic names with Standing in Nomenclature. http://www.bacterio.cict.fr

14. Breed RS. The Brevibacteriaceae fam. nov. of order Eubacteriales. Riassunti delle Communicazione VI. Congresso Internazionale di Microbiologia, Roma 1953; 1,13-14.

15. Ulrich $S$, Zbinden R, Pagano M, Fischler $M$, Speich R. Central venous catheter infection with Brevibacterium sp. in an immunocompetent woman: case report and review of the literature. Infection 2006; 34:103-106. PubMed http://dx.doi.org/10.1007/s15010-006-5027-6

16. Cannon JP, Spandoni SL, Pesh-Iman S, Johnson S. Pericardial infection caused by Brevibacterium casei. Clin Microbiol Infect 2005; 11:164-165. 
PubMed http://dx.doi.org/10.1111/j.14690691.2004.01050.x

17. McCaughey C, Damani NN. Central venous line infection caused by Brevibacterium epidermidis. J Infect 1991; 23:211-212. PubMed http://dx.doi.org/10.1016/0163-4453(91)92451-A

18. Manetos CM, Pavlidis AN, Kallistratos MS, Tsoukas AS, Chamodraka ES, Levantakis I, Manolis AJ. Native aortic valve endocarditis caused by Brevibacterium epidermidis in an immunocompetent patient. Am J Med Sci 2011; 342:257-258. PubMed http://dx.doi.org/10.1097/MAJ.0b013e31821ffb9f

19. Kumar VA, Augustine D, Panikar D, Nandakumar A, Dinesh KR, Karim S, Philip R. Brevibacterium casei as a cause of brain abscess in an immunocompetent patient. J Clin Microbiol 2011; 49:4374-4376. PubMed http://dx.doi.org/10.1128/JCM.01086-11

20. Field D, Garrity G, Gray T, Morrison N, Selengut J, Sterk P, Tatusova T, Thomson N, Allen MJ, Angiuoli SV, et al. The minimum information about a genome sequence (MIGS) specification. Nat Biotechnol 2008; 26:541-547. PubMed http://dx.doi.org/10.1038/nbt1360

21. Woese CR, Kandler O, Wheelis ML. Towards a natural system of organisms: proposal for the domains Archaea, Bacteria, and Eucarya. Proc Natl Acad Sci USA 1990; 87:4576-4579. PubMed http://dx.doi.org/10.1073/pnas.87.12.4576

22. Garrity GM, Holt JG. The Road Map to the Manual. In: Garrity GM, Boone DR, Castenholz RW (eds), Bergey's Manual of Systematic Bacteriology, Second Edition, Volume 1, Springer, New York, 2001, p. 119-169.

23. Stackebrandt E, Rainey FA, Ward-Rainey NL. Proposal for a New Hierarchic Classification System, Actinobacteria classis nov. Int J Syst Bacteriol 1997; 47:479-491. http://dx.doi.org/10.1099/00207713-47-2-479

24. Skerman VBD, McGowan V, Sneath PHA. Approved Lists of Bacterial Names. Int J Syst Bacteriol 1980; 30:225-420. http://dx.doi.org/10.1099/00207713-30-1-225

25. Buchanan RE. Studies in the nomenclature and classification of bacteria. II. The primary subdivisions of the Schizomycetes. J Bacteriol 1917; 2:155-164. PubMed

26. Zhi XY, Li WJ, Stackebrandt E. An update of the structure and 16S rRNA gene sequence-based definition of higher ranks of the class
Actinobacteria, with the proposal of two new suborders and four new families and emended descriptions of the existing higher taxa. Int J Syst Evol Microbiol 2009; 59:589-608. PubMed http://dx.doi.org/10.1099/ijs.0.65780-0

27. Breed RS. The families developed from Bacteriaceae Cohn with a description on the family Brevibacteriaceae Breed, 1953. Riassunti della Communicazione, VI Congresso Internazionale di Microbiologia, Roma 1953; $1: 1$ 10.

28. Ashburner M, Ball CA, Blake JA, Botstein D, Butler $\mathrm{H}$, Cherry JM, Davis AP, Drolinski K, Dwight SS, Eppig JT, et al. Gene ontology: tool for the unification of biology. The Gene Ontology Consortium. Nat Genet 2000; 25:25-29. PubMed http://dx.doi.org/10.1038/75556

29. GenBank database. http://www.ncbi.nlm.nih.gov:genbank

30. Lodders N, Kampfer P. A combined cultivation and cultivation-independent approach shows high bacterial diversity in water-miscible metalworking fluids. Syst Appl Microbiol 2012; 35:246252. PubMed

http://dx.doi.org/10.1016/j.syapm.2012.03.006

31. La Duc MT, Osman $S$, Vaishampayan P, Piceno Y, Andersen G, Spry JA, Venkateswaran K. Comprehensive census of bacteria in clean rooms by using DNA microarray and cloning methods. Appl Environ Microbiol 2009; 75:6559-6567. PubMed http://dx.doi.org/10.1128/AEM.01073-09

32. Guan TW, Zhao K, Xiao J, Liu Y, Xia ZF, Zhang XP, Zhang LL. Brevibacterium salitolerans sp. nov., an actinobacterium isolated from salt-lake sediment. Int / Syst Evol Microbiol 2010; 60:29912995. PubMed http://dx.doi.org/10.1099/ijs.0.020214-0

33. Tang SK, Wang Y, Schumann P, Stackebrandt E, Lou K, Jiang CL, Xu LH, Li WJ. Brevibacterium album sp. nov., a novel actinobacterium isolated from a saline soil in China. Int I Syst Evol Microbiol 2008; 58:574-577. PubMed http://dx.doi.org/10.1099/ijs.0.65183-0

34. Seng P, Drancourt M, Gouriet F, La Scola B, Fournier PE, Rolain JM, Raoult D. Ongoing revolution in bacteriology: routine identification of bacteria by matrix-assisted laser desorption ionization time-of-flight mass spectrometry. Clin Infect Dis 2009; 49:543-551. PubMed http://dx.doi.org/10.1086/600885

35. Prodigal. http://prodigal.ornl.gov 
36. Lowe TM, Eddy SR. tRNAscan-SE: a program for improved detection of transfer RNA genes in genomic sequence. Nucleic Acids Res 1997;

25:955-964. PubMed

37. Lagesen K, Hallin P, Rodland EA, Staerfeldt HH, Rognes T, Ussery DW. RNAmmer: consistent and rapid annotation of ribosomal RNA genes. Nucleic Acids Res 2007; 35:3100-3108. PubMed

http://dx.doi.org/10.1093/nar/gkm160
38. Krogh A, Larsson B. von HG, Sonnhammer EL. Predicting transmembrane protein topology with a hidden Markov model: application to complete genomes. J Mol Biol 2001; 305:567-580. PubMed http://dx.doi.org/10.1006/jmbi.2000.4315

39. Bendtsen JD, Nielsen H. von HG, Brunak S. Improved prediction of signal peptides: SignalP 3.0. J Mol Biol 2004; 340:783-795. PubMed

http://dx.doi.org/10.1016/j.jmb.2004.05.028 